\title{
The Cadaver Conundrum: Sourcing and Anatomical Embalming of Human Dead Bodies by Medical Schools during and after COVID-19 Pandemic: Review and Recommendations
}

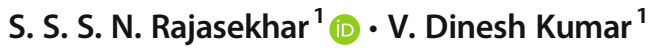

Accepted: 20 January 2021 / Published online: 1 March 2021

(C) The Author(s), under exclusive licence to Springer Nature Switzerland AG part of Springer Nature 2021

\begin{abstract}
COVID-19 pandemic has posed a new challenge for medical schools across the world regarding the acceptance of donated and unclaimed dead bodies for academic purpose. Uncertainty of the COVID-19 status among the donated bodies poses a health risk for embalming personnel and medical students who handle the embalmed cadavers. There is a paucity of literature delineating the criteria for accepting or rejecting the bodies during COVID-19 pandemic. Similarly, there is no recommended standard operating procedure for anatomical embalming during COVID-19. We propose certain criteria for accepting and rejecting the human dead bodies for anatomical embalming. And we propose some technical modifications to the conventional procedure of formalinbased anatomical embalming. A guarded approach and diligent screening of donated bodies is the way forward during the COVID-19 pandemic.
\end{abstract}

Keywords Body donation program $\cdot$ Cadaver $\cdot$ COVID-19 pandemic $\cdot$ Embalming $\cdot$ Medical education

\section{Introduction}

COVID-19 pandemic has posed a new challenge to the medical schools regarding the sourcing of human cadavers for medical education. The COVID-19 status remains unknown in a wide sector of the population until they are tested and there is also a possibility of asymptomatic cases who might have died due to associated comorbidities; when such dead bodies are donated for academic purpose, they pose as risk factors for the "body handlers," embalmers who handle the potentially infected body. The welfare and safety of the healthcare workers and staff involved in managing the dead bodies of COVID-19 should be paramount [1]. The World Health Organization (WHO) is doing a commendable job and is at the forefront of providing the guidelines and protocols to be followed for the management of patients and

This article is part of the Topical Collection on COVID-19

S. S. S. N. Rajasekhar sekhar5883@gmail.com

1 Department of Anatomy, Jawaharlal Institute of Postgraduate Medical Education, JIPMER, Puducherry 605006, India hospitals for COVID-19 pandemic; however, it has failed to recognize the issue of the use of donated dead bodies for academic purpose. The WHO interim guidance dated 24th March 2020, for the infection prevention and control for the safe management of dead body in the context of COVID-19 mentions that embalming should not be performed on the dead bodies either suspected or confirmed COVID-19 cases to avoid excess manipulation of the dead body [2]. However, there is no mention of the management protocols for dead bodies that are neither confirmed nor suspected of COVID19. Similarly, there is no mention of the voluntary whole-body donation programs or anatomical gift programs which cater to providing the dead bodies to the medical schools for academic and research purpose, including anatomical examination and dissection. Further, the WHO did not recommend any standard operating procedures and the embalming protocols to be followed before, during, and after the anatomical embalming [2].

The literature search regarding the issue of dead-body management during COVID-19 pandemic revealed only the guidance for individuals and families for managing the funeral during the COVID-19 pandemic by the United States Centres for Disease Control and Prevention (CDC), and the Governments of UK and Canada [2-5]. Similarly, the 
guidelines on dead body management during COVID-19 by the Government of India were only meant exclusively for the management of dead bodies of COVID-19 [6, 7]. Neither of the above-mentioned regulatory authorities have provided explicit guidance regarding the continuation or the suspension of voluntary whole-body donation programs by the medical schools nor the standard operating procedures to be followed before, during and after the anatomical embalming.

Continuing the pre-COVID-19 criteria for accepting the body donations or fitness assessment of the body donated for the academic purpose may turn out to be disastrous due to the omnipresent threat of SARS-CoV-2. Hence, there is a need to incorporate the COVID-19 factor into the screening criteria used in the voluntary body donation program and while accepting unclaimed bodies by the medical schools. Similarly, the conventional embalming solutions that are used in the pre-COVID-19 era for embalming may not ensure complete disinfection to neutralize the new threat of SARS-CoV2. Hence, continuing to use the same pre-COVID-19 era embalming solution for embalming the bodies during and after the COVID-19 pandemic will be a risky proposition for "body handlers", embalming personnel, medical students and ultimately medical schools. The duration of the COVID-19 pandemic has not been estimated yet and is considered to be a long-term problem according to the CDC [8]. So, to counter the threat of SARS-CoV-2 among the dead bodies received by the medical schools for academic purpose, there is a need for two-pronged approach consisting of (a) strategically focussed screening criteria for selecting/accepting the body donations and (b) purpose-designed embalming solution for the disinfection of the cadavers before, during, and after the anatomical embalming while effectively neutralizing the new threat of SARS-CoV-2. Even after the advent of vaccine for COVID19 , the unknown vaccination status among the voluntary donors and the unclaimed bodies that are going to be utilized for academic purpose makes the need for modified selection criteria and effective SARS-CoV-2 neutralizing embalming solution an all the more compelling proposition.

Here, we present various factors that are to be considered and screening criteria for selecting/accepting the whole-body donations and unclaimed bodies for academic purpose. We present a goal-oriented SARS-CoV-2 neutralizing embalming solution for effectively disinfecting the donated and unclaimed bodies. We also explore the different strategic technical modifications to the embalming procedure that are required to be adopted before, during, and after anatomical embalming of such cadavers and while storing them, subsequently. Such criteria will aid in avoiding the potential disruption in anatomy education using dissection of embalmed cadavers. This paper is intended for embalmers, dead body handlers, medical school administrators and policymakers involved in the management of dead bodies during COVID-19 pandemic and after the end of COVID-19 pandemic.

\section{Background}

\section{SARS-CoV-2 and COVID-19}

COVID-19 outbreak that began in later December 2019, and caused due to novel coronavirus (SARS-CoV-2) has an "incubation period" ranging from 1 to 14 days with an average of around 5 days [9]. The SARS-CoV-2 has known to be transmitted through airborne droplet particles and droplet nuclei [10]. It is also found to be transmitted through saliva, bronchoalveolar lavage, blood, urine, tears, faeces, sputum and sweat [11]. SARS-Cov-2 is also transmitted through invasive medical devices such as an endotracheal tube, tracheostomy, bronchoscopy and direct contact with an infected person, fomite transmission and transmission through invasive medical devices $[2,3,8]$. The virus is said to be active in the water for up to 7 days [12]. According to a report, the SARS-CoV-2 was found to be viable for up to $3 \mathrm{~h}$ in aerosols, $4 \mathrm{~h}$ on copper, $24 \mathrm{~h}$ on cardboard and 2-3 days on plastic and stainless steel [13].

Currently, there is a paucity of data available regarding the transfer efficiency of SARS COV-2 and the amount of time the virus remains infective from the dead bodies of confirmed COVID-19. In the case of influenza virus, the transfer efficiency was $31.6 \%$ of viral load to the hands with a contact of $5 \mathrm{~s}$ [14]. On the other hand, the transfer efficiency of parainfluenza virus 3 was $1.5 \%$ of viral load in $5 \mathrm{~s}$ [15]. Although there are some preliminary studies regarding the viability of SARS-CoV-1 on metals, plastic stainless steel and water, there is no convincing information regarding the viability of SARS-CoV-2 on glass, fluids such as sewage, ex vivo samples of blood $[12,13,16]$. In the case of a comparatively more lethal virus such an Ebola, the CDC of the USA recommends that the washing of the dead body, embalming and autopsy should not be performed [3]. Similarly, the invasive medical equipment such as implanted electronic medical devices, intravenous lines, endotracheal tubes and other tubes should not be removed from the dead body as it exposes the "body handlers" to an unwarranted risk [17].

\section{Implications of Voluntary Whole Body Donations for Teaching Medical Schools During COVID-19 Pandemic}

Teaching medical schools across the world are dependent on human cadavers for medical education and research including anatomical examination and dissection. Another important use of embalmed cadavers is that they are used for surgical skill training. Without cadaveric dissection, it was observed that the competency of the surgeons will be affected [18]. Each medical school across the world will have a continuous 
source of human cadavers through voluntary whole-body donation programs and the unclaimed dead bodies referred to the medical schools. Such procurement of human cadavers is done under various legal provisions of the Anatomy Act/ Unified Anatomical Gift Act [19]. The human dead bodies thus sourced will be utilized for teaching by dissection of the cadaver during each academic year. In India, an average of 10 human cadavers will be allotted for teaching the students of various health professional courses in a medical school. At the end of the teaching-learning exercise, the human cadaver will be utilized for the preparation of the wet gross anatomy specimens, osteology specimens and plastinates, which can, in turn, be used as teaching material. Essentially, each allotted human cadaver is completely utilized for teaching anatomy in an academic year. Thence, a fresh batch of human cadavers is required for each academic year. Due to the ongoing COVID19 pandemic, there is an anticipated scarcity of cadavers, which will affect the various human cadaver-based activities in the medical schools. Already there is lack of an adequate number of cadavers for teaching in medical schools due to the growing demand created by the increasing number of the medical students, and the COVID-19 pandemic will further worsen the situation [20].

The embalmed human cadavers are considered as the first patient for any medical student, where they gain an appreciation for the "fabric of the human body" [21]. Many students discover their passion for surgery while they are an anatomy student, and an inadequate or poor anatomy teaching was found to have an impact on students in not opting for a surgical speciality [22]. Therefore, the unavailability of cadavers due to COVID-19 pandemic may result in fewer people opting for surgery. We may miss out on some prospective top surgeons, and the consequences of inadequate good surgeons may be felt in the future [23]. The cadaver scarcity will also affect the learning process of current trainee anatomists and as a result of their inferior exposure to the dissection during their training, these trainee anatomists might not turn out to be confident enough to employ dissection as a teaching tool, when they become teachers of anatomy, and this may even hamper their employability [23].

A continuous supply of cadavers is a prerequisite for the preparation of prosections and skeletons, which cannot be otherwise prepared [24]. The unavailability of cadavers for teaching will invariably hamper the quality and modality of teaching anatomy [23]. The cadavers are used for learning surgical anatomy by the postgraduate students of general surgery, paediatric surgery, orthopaedics, cardiothoracic and vascular surgery, gastrointestinal surgery, surgical oncology and otorhinolaryngology. The soft embalmed cadavers are used for conducting surgical skill training programs for training surgeons of various specialities. Research in surgical anatomy and histology, as well as molecular research, is conducted using the cadavers or specimens obtained from the cadavers.
The cadavers are also required for biomedical engineering during the designing, development, and testing of new medical devices, where the measurements of and between the different anatomical structures are taken. Training of surgeons and allied medical professionals on using the newly developed biomedical devices will be done using the cadavers [25]. Thence, the cadavers are an invaluable resource for the medical school.

\section{Can we Do Away with Human Cadavers?}

Learning anatomy by dissection of embalmed human cadavers has been the "gold standard" in the medical curriculum [26]. It is an acknowledged fact that dissection of human cadaver enables the understanding of the 3D relationship of anatomical structures. The acquisition of anatomical knowledge by cadaveric dissection is considered as the most effective modality of learning. So, if there is feasibility, the face-toface teaching using dissected cadavers should be continued while maintaining social distancing guidelines during the pandemic [27].

\section{Options for Learning Anatomy Other than by Human Cadaveric Dissection}

Learning certain aspects of anatomy by methods other than the cadaveric dissection may be considered in the case of unavailability of cadavers and prosected cadaveric specimens due to reduced supply of dead bodies to the medical schools during or immediately after the COVID-19 pandemic. Owing to their portability and unconventional nature, learning tools such as plastinated specimens (sheet plastinates, whole organ plastinates and whole-body plastinates), plastic and fibreglass 3D models, anatomy videos, online anatomy resources, social media, 3D printed models, augmented reality (AR) and virtual reality (VR) models are being aggressively promoted. Often, they appear to be dominating the narrative in the teachinglearning paradigm; some anatomists are vehemently rejecting them, while some are vociferously recommending them. However, all modalities have their advantages and disadvantages. Plastinated models are handy, long-lasting and withstand a great amount of wear and tear. The preparation of plastinated specimens may not be feasible in all the medical schools, and plastinates cannot replace the cadavers [28]. Anatomy videos had brought learning content to the homes and laps of the students with the same costs involved in any number of reruns of the videos; this greatly aids in the revision of the content. However, learning anatomy by videos is considered as passive learning, and it was found that they do not increase the learning outcome among the students [29]. The social media such as Facebook ${ }^{\circledR}$, Twitter ${ }^{\circledR}$ and YouTube ${ }^{\circledR}$ have revolutionized the dissemination of the teaching and learning resources in anatomy to the masses. However, 
learning through social media will not help the lowperformance students [30], as it may require a great amount of self-control on their part to prevent themselves from straying into the entertainment paradigm owing to the commonality of the platforms. The YouTube ${ }^{\circledR}$ and other social media are mushrooming with anatomy learning content and sometimes the students are perplexed with a range of videos spanning from photographic content to schematic content. However, social media is not considered as a comprehensive resource for learning anatomy, as it is not bounded by any rules of the prescribed curriculum in anatomy. It may be at best useful for filling the gap in the knowledge for a layman who has limited access to conventional learning material [31, 32]. In spite of their huge cost, the $3 \mathrm{D}$ printed models can be quantitatively and qualitatively correlated with anatomical structures, but there is no evidence that they offer better learning outcomes compared with the cadaveric dissections [30, 33]. On the other hand, the advantage of increasingly popular technologies such as augmented reality (AR) and virtual reality (VR) is that the students are inherently motivated to use the technology for interactive learning [20]. The augmented reality (AR) offers an interactive three-dimensional representation of the anatomical model superimposed onto the physical objects in the real space, and learning using such medium was found to yield better test scores among students when compared to the dissection [34]. However, the estimated research outcome of "AR in anatomy" is yet to be comprehensively ascertained [35]. The virtual reality (VR)-based anatomy offers virtually generated desktop-based learning environment: however, it requires prior basic knowledge to comprehend the imagery [36]. Mixed reality offered by Microsoft Holo lens consists of a head mounted display that overlays the virtual objects on to a user's environment. It uses holographic projectors to place an image directly on wearer's retina. This technology enables participation in peer group learning, which is the main advantage of this technology [37]. Automated anatomical intelligence is a next-generation fusion imaging technique which processes ultrasound images captured by Philips EPIQ and Affiniti ultrasound systems with EchoNavigator (Philips Healthcare, Best, The Netherlands) software. This aids in creating a 3D image of the anatomical organs from a series of ultrasounds scans from different axes [38].

\section{The Disadvantages of Technology-Based and Online Anatomy Learning Platforms}

COVID-19 pandemic has abruptly transformed the delivery and the reception of education into a technology-based exercise, resulting in the creation of a huge cache of technologybased online content delivered through various media. But, basically, any technology-intensive learning tools are costly to procure and require a computer with good Internet bandwidth, which translates into a lot of initial investment in hardware and software for the creator and the consumer of the technology-based content. Most of the online anatomy software available today is costly and can only be subscribed by institutions and individuals with financial freedom, and it may not be the case for all the medical schools and students [21]. Although the online resources such as Netter 3D anatomy computer model may allow interactive learning, they may become tedious over the long run. Moreover, it was found that the students prefer to learn anatomy in a conventional manner rather than by using the Netter 3D anatomy $[39,40]$. When the cadaveric dissection and other technology-based modalities were compared for their learning outcomes, the students' scores were equivalent [30]. In addition, the effectiveness, benefits and the learning outcome of purposely created exclusive online programs are yet to be fully ascertained [23]. Hence, various tools used in teaching and learning of anatomy complement each other rather than act as a substitute. Moreover, prior basic knowledge in anatomy is required to use certain technology-based learning resources, which makes the cadaveric dissection an irreplaceable learning tool [30]. Mixed reality using Microsoft Holo lens involves huge initial investment cost for setting up and a dedicated support staff for maintenance. Moreover, it allows only a limited number of students to participate in learning at any given point of time, so it cannot be used for large class of students [37]. The use of Philips 3D automated anatomical intelligence is limited to the visualization of solid organs that can be scanned using ultrasound and cannot be used for studying entire anatomy of the body. The concept of blended learning, which uses the online resources for asynchronous or synchronous learning to complement the conventional face to face learning by the cadaveric dissections, will make the best use of all the available tools at our disposal [41, 42].

\section{The Technology-Based Learning Platforms: From the Students' Point of View}

Fundamentally, the learning of anatomy is a multi-modal, innovative and engrossing activity. So, the technology-based education of anatomy can only assist but cannot replace dissection because medical students have to learn to dissect on the cadaver which enables them to operate on real patients [43]. Similarly, the online learning material present in any form will give considerably decreased levels of selfperceived learning and satisfaction compared with the cadaveric dissection [44]. Similarly, excessive reliance on the online anatomy learning material will deprive the students of social interaction and team building which the face-face learning will offer to the student $[23,45]$. Sometimes, online learning resources and technology-based learning may bring about disengagement and feeling of isolation among the students [46]. 


\section{The Impact of Cadaveric Dissection on the Students}

Cadaveric dissection provides hands-on experience in comprehending complex 3D arrangement of anatomical structures which can be learned experientially, provides an insight into anatomical variations and helps to develop compassion and empathy for the patient $[43,45]$. There will be a lot of hidden curriculum that the student learns when he is dissecting the cadaver. The dissections will foster the non-traditional, discipline-independent skills (NTDIS) in the students which are all the more important to wade through the testing times such as the COVID-19 pandemic [23, 45]. Apart from that, cadaveric dissection is considered as an invaluable resource for cultivating fine motor skills in a stress-free environment [47]. The dissection of human cadaver fosters team-based learning and creates the team players out of doctors which is quintessential in an operation room setting. Working with cadavers in the dissection laboratory along with peers, teacher, technicians, academics and the body donors will help students develop their emotional intelligence, situational awareness, professional behaviour, personal feeling of love and empathy [23]. Apart from its use in learning anatomy, the cadaveric dissection also has a role in ethics and humanity [48], as it is known to influence the ethical perceptions of the medical students which inculcate the concept of dignity, beneficence, consent, and justification versus the necessity of dissection and contrast between objectification and personification [49]. Already, the current level of exposure of students to cadaveric dissection is inadequate from an aspiring surgeons' point of view [50]. And completely, ditching the cadaveric dissection will be disadvantageous to the competency of prospective surgeons [18].

\section{Student's Preference}

Students prefer to learn anatomy by cadaveric dissection over the other available methods $[28,39,49,51]$. Medical, dental and biomedical science students consider that cadaveric dissection and prosections to be critical to their development into a complete professional [52]. Hence, it is clear that the cadaveric dissection is indispensable for a medical student despite the hindrances caused in the procurement of cadavers due to the ongoing COVID-19 pandemic. So, it is incumbent on the medical schools to seek means to procure an adequate number of cadavers to cater to the needs of medical students of various courses.

\section{Factors Responsible for Decreased Input of Human Dead Bodies to Medical Schools during COVID-19 Pandemic}

1. Many medical schools across the world have suspended the voluntary whole-body donation program/willed body programs and are not accepting donated bodies [43, 53-55].

2. Registrations for voluntary whole-body donations by the prospective donors will come down because of the fear of approaching the medical schools, where COVID-19 patients are being treated [56]. Almost all the medical schools across India are being converted into COVID-19 hospitals for the admission and the treatment of COVID19 cases [57, 58].

3. Deaths at home due to non-COVID-19 reasons: The next of kin of the deceased will be reluctant to visit the hospital for the process for donation (not pre-registered, 11th-hour donations after the death) because of the fear of approaching medical schools where COVID-19 patients are being treated.

\section{The Nuances of Accepting Human Dead Bodies by the Medical Schools During COVID-19 Pandemic}

Embalmed cadavers are paramount in teaching anatomy to the students, and non-infectious cadavers are essential for teaching anatomy during and immediately after the COVID-19 pandemic [43]. The decision to accept or reject the voluntary whole-body donation and unclaimed bodies for academic purpose is indeed a challenging one for the medical schools. This is because of two explicit reasons: (a) the unknown COVID19 status of the body and (b) the possibility of donor being an asymptomatic carrier of COVID-19. Because of this, every dead body can be a potentially infectious one for the embalming personnel while receiving and embalming the body. Moreover, there is a paucity of literature regarding the transmission efficacy of SARS-CoV-2. Because of too many unknowns regarding the SARS-CoV-2 and the lack of recommendations or standard operating procedures from the regulatory authorities regarding the sourcing and embalming the dead bodies, the decision to accept or reject the donated bodies is all the more difficult one.

Certain medical schools across the USA and Europe such as the Cleveland Clinic, University of Aberdeen, University of Cambridge, University of Dundee, Royal College of Surgeons in Ireland, University of Edinburg, University of Glasgow, Imperial College of London, University of Nui Galway, University of Oxford and other medical colleges including that of the authors have suspended their body donation programs $[23,53,54,59,60]$. However, the University of Munich (LMU) has not suspended the body donation program, but potentially SARS-CoV-2-infected body donors are not being accepted. Moreover, all the donations were screened by COVID-19 testing before they are accepted [53]. 
On the other hand, some medical schools in Australia and New Zealand, which are "open for business" with a status of "business as usual", have admitted the students to a new academic year starting from February/March 2020 and continue to teach human anatomy face to face laboratory practical sessions through dissection of cadavers [55]. The University of Chicago, USA, is also continuing to accept body donations and teaching the students using cadaveric dissection despite the COVID-19 pandemic [43]. In the context of the business, as usual, there have been reports where there were enquiries made with the medical school if the deceased body of COVID-19 patient would be accepted as an anatomical gift [53]. Furthermore, there have been instances where the donated bodies have been accepted during the initial stages of the COVID19 pandemic without ascertaining the COVID-19 status of the body with a confirmatory test [53]. It is an agreeable fact that such situations are quite dangerous for the personnel involved in embalming. Moreover, a negative nasopharyngeal and oropharyngeal swab test does not rule out COVID-19 [61], which implies that there is no safe way to delineate suspected/ confirmed COVID19 cases from that of the uninfected ones. Given such circumstances, a blanket rejection of all the donated bodies during the COVID-19 pandemic will not be a viable strategy and may lead to acute scarcity of embalmed cadavers in medical schools. And teaching using dissection of cadavers may be affected, when the medical schools return to conventional working patterns, after the end of the pandemic [55].

It is incumbent on the administrators of the medical school and department of anatomy to provide a safe environment for both staff and the students during the COVID19 pandemic and immediately after the end of the pandemic. The embalming staff are at the risk of exposure to virus if the voluntary body donor or the unclaimed body donated to the department anatomy is a carrier of SARS-CoV-2. Similarly, students handling the embalmed cadavers will be at the risk if there is inadequate disinfection of the donated cadavers during embalming. The crux of the matter lies in the quick identification of the potentially risky circumstances where the exposure to SARS-CoV-2 is more, and if necessary, a temporary suspension of voluntary body donation programs to decrease the health risks of the community [55]. Hence, there is a clear need to review the existing policy and selection criteria for accepting voluntary body donations and unclaimed bodies by medical schools during and sometime after the COVID-19 pandemic. A new and comprehensive cadaver management strategy for donor screening and embalming may mitigate the risks of COVID-19 and maintain the steady supply chain of dead bodies for the medical schools.
The Challenges Faced by the Medical Schools While Sourcing Human Dead Bodies during COVID-19

\section{Pandemic}

1. Unknown COVID-19 status of all the voluntary donations, if the place of death of the deceased is at home or any other place other than a hospital

2. Unknown COVID-19 status of all the unknown and or unclaimed dead bodies, if the place of death of the deceased is at home, prison, public place, or any other place other than a hospital

3. Cases of death at a hospital without a definitive and confirmed diagnosis (Unknown COVID-19 status)

4. Cases where the immediate or antecedent medical cause of death is a respiratory illness

5. Cases where the diagnosis of the presenting illness is not made, e.g. cases such as fever for evaluation

\section{Asymptomatic and Pre-Symptomatic Cases of COVID-19}

The incidence of asymptomatic COVID-19 cases ranges from 11 to $17 \%[62,63]$. It was reported that the asymptomatic carriers and the COVID-19 cases during their incubation period were contagious [64]. The uncertainty regarding the COVID-19 status calls into a question of whether to accept the voluntarily donated and unclaimed bodies during the time of the pandemic.

\section{Safe Bets for Accepting Dead Bodies by Medical Schools for Educational Purpose (Anatomical Embalming)}

To avoid undesirable consequences, we propose certain selection criteria for accepting voluntary body donations and unclaimed bodies by the medical schools for academic purpose.

Voluntary whole-body donations or unclaimed bodies may be accepted if it meets the following criteria:

1. If the place of death is at a hospital

2. If the immediate or antecedent medical cause of death is not COVID-19

3. If the patient is tested for COVID-19 and found to be negative during hospitalization for the terminal illness

However, even if the body donation is accepted or declined, the dignity of the deceased and the next of kin should be respected at all times [1].

\section{SARS-CoV-2 and Disinfection}

Disinfection is the cornerstone for embalming the bodies during and some time after the COVID-19 pandemic. Reportedly 
SARS-CoV has different viable periods on different surfaces. On materials such as metal, glass and plastic, the SARS-CoV1 is found to be viable and infectious ranging from $2 \mathrm{~h}$ up to 9 days [65]. SARS-Cov-2 was found to be present and viable in urine and stool specimens $[9,66]$. Hence, disinfection of embalming instruments, embalming surfaces, embalming facility and the embalming personnel should be based upon the viability potential of the SARS-CoV-2.

\section{Recommended Protocol for Anatomical Embalming}

In earlier outbreaks of the virus infections such as SARS, MERS and EBOLA, there is a blanket ban on using the bodies for academic purpose [62]. Moreover, the earlier virus outbreak did not reach the extent of COVID-19 pandemic; hence, there was no threat of a shortage of voluntary body donations to the medical schools for academic purpose. On the other hand, COVID-19 has been declared a global pandemic [10]. In the absence of explicit guidelines, we propose the following recommendations for embalming of voluntarily donated or unclaimed human dead bodies used for medical education and research purpose using CDC recommendations and WHO protocol for conducting the post-mortem autopsy during COVID-19 pandemic as a guidance $[2,3,10]$.

\section{Pre-Embalming Considerations}

\section{Strategic Approach}

People who handle dead bodies have a perennial risk of contracting infection from the dead bodies [67, 68]. So, consider all the dead bodies to be infectious of SARS-CoV-2 until proven otherwise and follow safe work practices. The dead bodies should be mandatorily tested for COVID-19 by postmortem nasopharyngeal (NP) swab before taking up for embalming. Only a limited number of embalming personnel should be working at any given point of time. Personnel with age above 60 and/or immunocompromised should not be allowed to handle the body [69]. Wear PPE during the anatomical examination for ascertaining the fitness of the body for anatomical embalming [53].

Sometimes, in the case of post-mortem autopsied bodies, the next of kin of the deceased may not be ready to take the body to home or for cremation and may be requesting the medical school authorities to accept the autopsied body as a donation for medical education and research. Any such requests should be categorically denied as the post-mortem autopsied bodies are inherently unfit for academic embalming and use for teaching medical students. As a rule, all the autopsied bodies should not be accepted for anatomical embalming, even if the next of kin of the deceased is requesting for such donation.

\section{Risk to Body Handlers}

There are reports of "body handlers" contracting COVID-19 from the infected dead body they were handling; hence, the safety of the personnel should not be taken lightly [70, 71]. The body handlers are at the constant risk of being infected while transporting and handling the bodies of unknown COVID-19 status. Although the chances of aerosol generation are very unlikely after death, there is a chance for leakage of body fluids that are highly contagious. So, body handlers should be mindful of leakage of body fluids during all times. The body handlers are at the risk of exposure during the following scenarios: (a) shifting the patient from hospital bed to body bag before transportation, especially with invasive medical devices still in place; (b) leakage from body bag in case of a faulty body bag seal; (c) the splashing of body fluids that are collected within the body bag while opening the zipper of body bag or while removing the body from the body bag; and the (d) removal and disposal of invasive medical devices. Hence, it is prudent for the body handlers to have $1 \%$ sodium hypochlorite solution always at their disposal for emergency use to deal with unanticipated mishaps (to disinfect the surface of the body, leaked body fluids, and invasive medical devices).

\section{Personal Protective Equipment (PPE) Recommendations for Embalming Personnel}

The personal protective equipment that is mandated for handling the suspected and confirmed COVID-19 cases [10] should be worn by all the personnel who receive the dead body irrespective of COVID-19 status. Similarly, the personnel who are inspecting the donated bodies or the unclaimed bodies for assessing the fitness for academic purpose should also wear PPE during the entire process of assessment. The embalming personnel who are embalming the selected bodies should wear the PPE before, during and after the completion of embalming and until the transfer of the embalmed cadaver to the cadaver storage tank and cleaning of embalming facility thereafter.

1. Wear a clean, fluid-resistant, long-sleeved hospital isolation gown to protect skin and clothing with shoe and hair covers.

2. Wear puncture proof heavy duty gloves over double nitrile gloves while handling the body and embalming instruments.

3. Use a plastic face shield to protect eyes, nose and mouth from splashing of body fluids.

4. Use the NIOSH-approved N95 respirator recommended for use in COVID-19. 
5. Follow correct donning and doffing procedure recommended by WHO while using PPE.

\section{Testing}

All bodies should be mandatorily subjected to post-mortem testing for COVID-19 before they are accepted for anatomical embalming [53]. Even after the availability of the vaccine for COVID-19 or after the end of COVID-19 pandemic, the vaccination status of the voluntarily donated body or the unclaimed body may not always be available before embalming. Hence, it is imperative that all the bodies should be considered as a potentially infectious and tested post-mortem for COVID-19. The bodies can be tested by obtaining post-mortem nasopharyngeal (NP) swab. In case of difficulty in obtaining the NP swab, an oropharyngeal (OP) specimen or nasal mid-turbinate (NMT) swab or anterior nares (nasal swab; NS) specimen or nasopharyngeal aspirate or nasal aspirate (NA) specimen should be obtained and subjected to COVID-19 testing. Strictly adhere to the protocols recommended for biosafety and infection control practices while collecting and handling the specimens.

\section{Storage}

Store the dead bodies in a double body bags at $4^{\circ}$ centigrade in a cold chamber separately designated to hold COVID-19 dead bodies, until the COVID-19 test results are obtained. For storage and handling the dead bodies, an integrated layered body bag is recommended to reduce the exposure of infected body fluids to the "body handlers" [72].

\section{Preparation of Embalming Chemicals}

Conventional embalming fluid contains components such as formaldehyde/formalin (primary component, preservative, antibacterial and antiviral), ethanol (preservative, antibacterial and antiviral), methanol (preservative, antibacterial and antiviral), phenol (antibacterial, anti-fungal, antiviral and preservative), Thymol (antifungal), glycerine (humectant), sodium borate (pH Buffer), sodium citrate (anticoagulant), eucalyptus oil (perfume) and eosin (colouring agent).

\section{Embalming Fluids and their Effect on SARS-CoV-2}

Formaldehyde inactivates the virus by combining with nonprotonated amino acid groups such as lysine to form hydroxymethylamine. Hydroxymethylamine creates inter- or intramolecular methylene crosslinks by combining with amino, amide, guanidyl, phenolic or imidazole groups of amino acids [73]. It is reported that the SARS-CoV-1 was neutralized by the use various disinfectants such as Ethanol: $62-71 \%$ (within $30 \mathrm{~s}$ ), Hydrogen Peroxide: $0.5 \%$ (within $1 \mathrm{~min}$ ) or
Sodium Hypochlorite: $0.21 \%$ (within 30 s), Formaldehyde: $0.7-1 \%$ (within $2 \mathrm{~min}$ ), Gluteraldehyde: $0.5-2.5 \%$ (within $5 \mathrm{~min}$ ) have inactivated the SARS-CoV-1 [65].

\section{Recommended Composition of the Arterial Injection Solution for Anatomical Embalming}

Ethanol: $2000 \mathrm{ml}$, Phenol: $500 \mathrm{ml}, 0.5 \%$ Sodium Hypochlorite solution: $5 \mathrm{ml}$, Formalin: $1400 \mathrm{ml}$, Hydrogen Peroxide: $50 \mathrm{ml}$, Glycerine: $3000 \mathrm{ml}$, Sodium borate: $45 \mathrm{~g}$, Sodium Citrate: $45 \mathrm{~g}$, Thymol: $25 \mathrm{~g}$, Eucalyptus oil: $10 \mathrm{ml}$, Eosin: 2 pinches, Distilled water: $2940 \mathrm{ml}$, to constitute a total of $10,000 \mathrm{ml}$ to embalm a cadaver with an average weight of $70 \mathrm{~kg}$. Phenol is the primary component of cavity embalming solution and used in compartmental embalming in the case of gangrene for it has a superior disinfection capability [74]. Phenol is used in 5\% concentration as a disinfectant in the embalming solution. Hence, ethanol- and phenol-based embalming solution would effectively neutralize the SARS$\mathrm{CoV}-2$ in the shortest period.

\section{Recommended Composition of Cadaver Storage Tank Solution}

Formalin: 14\%, Glycerine: 14\%, Phenol: 1\%, Sodium Hypochlorite solution: $0.5 \%$, Thymol $500 \mathrm{~g}$ for $1000 \mathrm{lof}$ tank solution. However, one must be aware that the inclusion of sodium hypochlorite solution (bleach) in the arterial solution and tank solution may result in minced meat appearance of histological sections obtained from the cadavers.

\section{Preparation of Bleach}

Bleach can be prepared by using a dilution of 1:100 of 5\% sodium hypochlorite solution resulting in a final concentration of $0.1 \%$ hypochlorite solution which is effective against SARS-CoV-2 within 1 min. A dilution of 1:50 of standard bleach is recommended for SARS-CoV-1 [65]. For disinfecting the body fluids, the exterior of dead body and faeces, $0.5 \%$ of sodium hypochlorite solution (equivalent to $5000 \mathrm{ppm}$ ) is recommended [3].

\section{Cadaver Preparation and Embalming}

\section{Receiving the Body}

The personnel receiving and handling the body should be clad with PPE that is mandated for use in COVID-19. The friends and family members of the deceased donor should not be allowed to come in contact with "body handlers" for an extended period [75]. Social distancing should be maintained while receiving the donated body of the deceased. The body should be transported in a double body bag (minimum 
thickness of $6 \mathrm{~mm}$ ). Only a single person should handle the body at a time. Remove all the personal artefacts and sharp objects if any from the body. Strictly adhere to standard precautions to prevent percutaneous injury and direct contact with infectious material such as body fluid discharges. After removing the invasive medical devices, disinfect the puncture holes or wounds by using $1 \%$ hypochlorite solution [69].

\section{Surface Disinfection}

There is need for extensively and thoroughly disinfecting the bodies particularly the oral cavity, nasal cavities and oropharynx with disinfectant viricidal solutions during embalming before they are used for teaching [43]. Use a $0.5 \%$ sodium hypochlorite solution as a surface disinfectant. Strictly avoid all aerosol-generating procedures (AGPs) such as splashing of water while cleaning the body or cleaning the oronasal, anal and vaginal purge. Disinfect the external surface of the body bag by gently irrigating with the disinfectant. Remove the body from the body bag and gently irrigate the external surface of the body with the disinfectant. Remove the invasive medical devices, if any and put them in a plastic bag containing an adequate amount of disinfectant. Thoroughly irrigate the external orifices of the body. Induce oronasal, vaginal (female) and anal purge by exerting pressure on the anterior abdominal wall to evacuate the body fluids. Utmost care should be taken to avoid contact with body fluids as SARS$\mathrm{CoV}-2$ has been detected in the faeces of COVID-19-positive patients and considered infectious $[3,76]$. Neutralize the exuded purge/body fluids by adding $0.5 \%$ sodium hypochlorite solution before they are let into common drainage. Shave the body hair from the cadaver, irrigate the entire body once again with disinfectant and thoroughly wash the body with water. The entire procedure of surface disinfection is notoriously prone for generating splashes. Avoid using compressed air and/or water under pressure for cleaning which may cause splashing and re-aerosolize the infectious material. Hence, utmost care should be taken to avoid splashing.

\section{Recommendations for Embalming Procedure}

Position the body on the embalming table. Use caution while handling scalpel and needles. Use the femoral artery or common carotid artery to inject the arterial solution. Do not perform drainage through veins. After completion of the arterial injection, suture the arterial access area carefully avoiding any needle prick injuries. Inject $20 \mathrm{ml}$ of arterial solution into the cranial cavity by using long needle and syringe passed through inner canthus of the eye and superior orbital fissure. For hypodermic and surface embalming, use the concentrated arterial solution devoid of water. After completion of embalming, once again induce oronasal, vaginal and anal purge by applying pressure on the anterior abdominal wall. After draining the purge, thoroughly irrigate and wash the cadaver. Shift the cadaver carefully without splashing into a designated cadaver storage tank for cadavers received during COVID-19 pandemic.

\section{Disinfection, Cleaning and Disposal after Embalming}

After completion of embalming, continue to wear the PPE while cleaning and disposing of the biomedical waste and use additional layers of protection, if required.

\section{Disposal of Body Fluids/Purge Generated during Embalming}

If the purge is collected within the embalming station, add $0.5 \%$ sodium hypochlorite solution to neutralize the purge before draining.

\section{Disposal of Invasive Medical Devices}

The invasive medical devices such as catheters, intravenous cannula, nasogastric tubes, tracheostomy tubes and personal artefacts that are removed from the body are highly contagious and should be handled with care. They should be disposed-off responsibly according to the existing hospital protocol for disposal of biomedical waste after the completion of embalming. Dispose the scalpel, needles, and all other sharps in a labelled, puncture-proof, and closable container.

\section{Terminal Disinfection}

Disinfect the embalming equipment, embalming station and embalming room using $0.5 \%$ sodium hypochlorite solution. PPE should be worn by the personnel throughout the entire cleaning procedure.

\section{Disinfection of Embalming Instruments}

The recommended composition of disinfection solution for embalming equipment is $1 \%$ formalin, $1 \%$ phenol, $1 \%$ ethanol and $0.5 \%$ sodium hypochlorite solution. Surgical instruments used for embalming should be continuously placed in a tray containing disinfectant solution while performing embalming. After completion of embalming, the embalming instrument should be soaked in the above disinfection solution for 6$8 \mathrm{~h}$ before washing and storing them.

For cleaning large contaminated areas, $0.5 \%$ sodium hypochlorite solution should be used. Any gross contamination and liquids should be collected using the absorbent material.

\section{Disposal of PPE}

Doff the PPE carefully and dispose-off in a bio-hazard bag (yellow bag). Then, irrigate the interior of the bag with $0.5 \%$ sodium hypochlorite solution and tie the mouth of the 
bag. Following this, irrigate the exterior of the bag with the same disinfectant solution [6].

\section{Personal Cleaning}

After the cleaning of embalming facility and disposal of the PPE, wash hands immediately with soap and water for $20 \mathrm{~s}$ followed by sanitizing the hands with alcohol-based hand rub containing at least $60 \%$ alcohol. Avoid touching face, eyes and nostrils with gloved or unwashed hands. Make sure that washing and hand sanitizing area is accessible and in proximity to the place of disposal of PPE. The protocol to be followed for anatomical embalming during and immediately after COVID-19 pandemic is summarized in Fig. 1.

\section{Recommendations for Embalming Facility}

Maintain a logbook and enter the details of date, names and activities of all the personnel participating in the embalming and cleaning of embalming facility. Perform embalming in a well-ventilated room which has natural airflow of at least 1601 per second per person and with a controlled direction of airflow. Maintain a negative air pressure differential greater than $2.5 \mathrm{~Pa}(0.01$-in. water gauge) or an airflow differential greater than 56 1/s $(125 \mathrm{cfm})$ exhaust versus supply in the embalming room compared with the surrounding areas. All the air should be exhausted to outside directly or through a high-efficiency particulate air (HEPA) filter. In an air-controlled facility, have at least 12 air changes per hour $(\mathrm{ACH})$ not only during the embalming but also during the cleaning process of embalming facility [77]. After the completion of embalming, continue ventilation and air changes till the cleaning the embalming facility is complete.

Sometimes there may be requests from the next of kin of the deceased donor for visiting the body of the deceased after embalming, if they did not get a chance to bid farewell to the deceased before donation. All such requests should be denied complying with social distancing norms during COVID-19
Fig. 1 Schematic of protocol to be followed for anatomical embalming during and immediately after COVID-19 pandemic

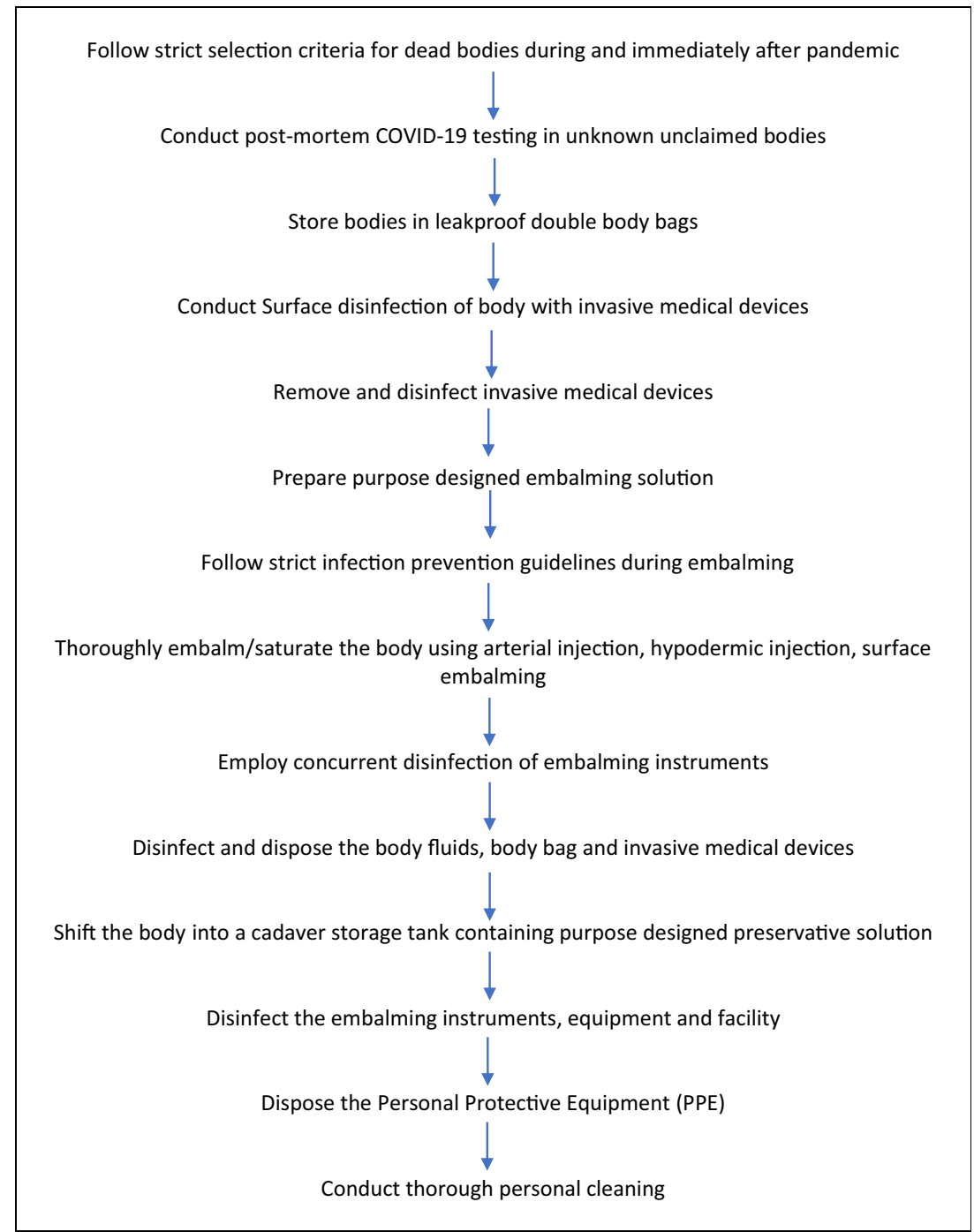


pandemic as they may be asymptomatic carriers of the SARSCOV-2.

\section{Training and Awareness}

All the personnel who handle the body during storage, transportation and embalming as well as the personnel who are involved in cleaning the embalming facility should be trained in the infection prevention and control practices. Train all the embalming personnel and the cleaning staff on the basics of transmission risk of SARS-CoV-2, infection prevention and control practices, cautious usage of hazardous chemicals, rational use of PPE, correct PPE donning and doffing techniques, correct disinfection and cleaning techniques and techniques to avoid AGP.

\section{Funeral Embalming and Forensic Post-Mortem Autopsy}

The COVID-19 prevention protocols suggested for handling the body during anatomical embalming can also be extrapolated to and used while conducting funeral embalming or while performing the forensic post-mortem autopsy, since the body handling procedures for all three procedures are practically the same. In funeral embalming, venous drainage will be accompanied by arterial injection of the embalming solution. Care should be taken to disinfect and dispose the body fluids and blood extruded form venous drainage. In forensic post-mortem autopsy, the body is cut open in the midline to access the thoracic, abdominopelvic cavities and the cranial cavity. Care should be taken while separating and dissecting each organ for inspection. Strict infection prevention guidelines mandated for COVID-19 including PPE should be followed during autopsy as the lungs are cut open during the autopsy which may release the air trapped within the alveoli as aerosols. After inspection, the remainder of the viscera should be placed in the plastic visceral bag filled with preservative solution (cavity fluid) including $1 \%$ sodium hypochlorite to ensure neutralization of SARS-CoV-2. Biomedical waste should be disinfected before it is disposed as per existing guidelines.

\section{Conclusion}

Shortage of human cadavers will hamper the medical education not only during the COVID-19 pandemic but also during the post-pandemic period. Adopting pre-COVID-19 screening criteria for accepting donated bodies may be risky during COVID-19 pandemic. Similarly, pre-COVID-19 embalming protocol may not be adequate to disinfect the bodies for SARS-CoV-2. An alternative strategy needs to be adopted to overcome the shortage of human cadavers in the near future.
There is a need to rigorously screen the body donations for COVID-19 before accepting for academic purpose during the COVID-19 pandemic and after the end of the pandemic, because of the unknown vaccination status of the donated body. Appropriate COVID-19-specific modifications to the protocols of anatomical embalming may be the way forward for mitigating the risk posed by the SARS-CoV-2 for the personnel handling the cadavers.

Authors' Contributions Rajasekhar SSSN -Conceptualisation, Manuscript Writing, Manuscript Editing. Dinesh Kumar VManuscript writing.

Data Availability Not applicable.

Code Availability Not applicable.

\section{Declarations}

Ethics Approval Not applicable, since it is a review article.

Consent to Participate Informed consent is not applicable since it is a review article.

Consent for Publication The manuscript does not contain any personal data; hence, consent is not applicable.

Conflicts of Interest/Competing Interests On behalf of all authors, the corresponding author states that there is no conflict of interest.

\section{References}

1. Finegan O, Fonseca S, Guyomarc'h P, Morcillo Mendez MD, Rodriguez Gonzalez J, Tidball-Binz M, et al. ICRC advisory group on the management of COVID-19 related fatalities (2020). International Committee of the red Cross (ICRC): general guidance for the management of the dead related to COVID-19. Forensic Sci Int Synergy. 2020;31(2):129-37.

2. World Health Organisation. Infection Prevention and Control for the safe management of a dead body in the context of COVID-19 Interim guidance. 2020. Available at: https://apps.who.int/iris/ bitstream/handle/10665/331538/WHO-COVID-19-1PC DBMgmt-2020.1-eng.pdf (Accessed: 20 August 2020).

3. World Health Organisation. Water, sanitation, hygiene, and waste management for the COVID-19 virus. Interim guidance. 2020. Available at:https://apps.who.int/iris/rest/bitstreams/1272446/ retrieve (Accessed: 20 August 2020).

4. Government of United Kingdom. Guidance for care of the deceased with suspected or confirmed coronavirus (COVID-19) 2020. Available at: https://www.gov.uk/government/publications/covid19-guidance-for-care-of-the-deceased/guidance-for-care-of-thedeceased-with-suspected-or-confirmed-coronavirus-covid-19 (Accessed 20 August 2020).

5. Government of Canada. COVID-19: Death care services and handling of dead bodies during the pandemic: Interim guidance.2020. Available at: https://www.canada.ca/en/public-health/services/ diseases/2019-novel-coronavirus-infection/guidance-documents/ death-care-services-handling-dead-bodies.html (Accessed 20 August 2020). 
6. Government of India. Ministry of Health and family welfare. Coronavirus Disease 2019 (COVID-19): Standard Operating Procedure (SOP) for transporting a suspect/confirmed case of COVID-19. 2020. Available at: https://www.mohfw.gov.in/pdf/ StandardOperatingProcedureSOPfortransportingasuspectorconfirmed caseofCOVID19.pdf (Accessed: 20 August 2020).

7. Ravi KS. Dead body management in times of Covid-19 and its potential impact on the availability of cadavers for medical education in India. Anat Sci Educ. 2020;13(3):316-7.

8. Centers for Disease Control and Prevention (CDC). Coronavirus Disease 2019 (COVID-19): Healthcare workers: Pandemic Planning Scenarios.2020. Available at: https://www.cdc.gov/ coronavirus/2019-ncov/hcp/planning-scenarios.html (Accessed 20 August 2020).

9. Sun J, Zhu A, Li H, Zheng K, Zhuang Z, Chen Z, et al. Isolation of infectious SARS-CoV-2 from urine of a COVID-19 patient. Emerg Microbes Infect. 2020;9(1):991-3.

10. Centers for Disease Control and Prevention (CDC). Coronavirus Disease 2019 (COVID-19): Transmission. 2020. Available at: https://www.cdc.gov/coronavirus/2019-ncov/prevent-getting-sick/ how-covid-spreads.html (Accessed 20 August 2020).

11. Mohseni AH, Taghinezhad-SS XZ, Fu X. Body fluids may contribute to human-to-human transmission of severe acute respiratory syndrome coronavirus 2: evidence and practical experience. Chin Med. 2020;15:58.

12. Tran HN, Le GT, Nguyen DT, Juang RS, Rinklebe J, Bhatnagar A. SARS-CoV-2 coronavirus in water and wastewater: a critical review about presence and concern. Environ Res. 2020;1:110265.

13. Van Doremalen N, Bushmaker T, Morris DH, Holbrook MG, Gamble A, Williamson BN, et al. Aerosol and surface stability of SARS-CoV-2 as compared with SARS-CoV-1. N Engl J Med. 2020;382(16):1564-7.

14. Bean B, Moore BM, Sterner B, Peterson LR, Gerding DN, Balfour HH Jr. Survival of influenza viruses on environmental surfaces. J Infect Dis. 1982;146(1):47-51.

15. Ansari SA, Springthorpe VS, Sattar SA, Rivard S, Rahman M. Potential role of hands in the spread of respiratory viral infections: studies with human Parainfluenza virus 3 and rhinovirus 14. J Clin Microbiol. 1991;29(10):2115-9.

16. Ding Y, He L, Zhang Q, Huang Z, Che X, Hou J, et al. Organ distribution of severe acute respiratory syndrome (SARS) associated coronavirus (SARS-CoV) in SARS patients: implications for pathogenesis and virus transmission pathways. J Pathol. 2004;203:622-30.

17. Henwood AF. Ebola and histotechnologists. J Histotechnol. 2018;41:71-3.

18. Memon I. Cadaver dissection is obsolete in medical training! A misinterpreted notion. Med Princ Pract. 2018;27:201-10.

19. Rajasekhar SSSN, Aravindhan K, Gladwin V, Chand P. Body donation- consent from non-related persons: case series, review, and recommendations. J Clin Diagn Res. 2016;10:AR01-4.

20. Saverino D. Teaching anatomy at the time of COVID-19. Clin Anat. 2020. Available at: https://doi.org/10.1002/ca.23616.

21. Gregory SR, Cole TR. The changing role of dissection in medical education. JAMA. 2002;287:1180-1.

22. The Independent: Lack of anatomy training could lead to shortage of surgeons. Available at: https://www.independent.co.uk/lifestyle/health-and-families/health-news/lack-of-anatomy-trainingcould-lead-to-shortage-of-surgeons-9570684.html (Accessed 20 August 2020).

23. Franchi T. The impact of the Covid-19 pandemic on current anatomy education and future careers: a student's perspective. Anat Sci Educ. 2020;13(3):312-5.

24. Sugand K, Abrahams P, Khurana A. The anatomy of anatomy: a review for its modernization. Anat Sci Educ. 2010;3:83-93.
25. Singal A, Bansal A, Chaudhary P. Cadaverless anatomy: darkness in the times of pandemic Covid-19. Morphologie. 2020;104:14750 .

26. Hildebrandt S. Lessons to be learned from the history of anatomical teaching in the United States: the example of the University of Michigan. Anat Sci Educ. 2010;3:202-12.

27. Byrnes KG, Kiely PA, Dunne CP, Mcdermott KW, Coffey JC. Communication, collaboration and contagion: "Virtualisation" of anatomy during COVID-19. Clin Anat. 2020. Available at: https://doi.org/10.1002/ca.23649.

28. Azu O, Peter A, Etuknwa B, Ekandem G. The awareness of medical students in Nigerian universities about the use of plastinated specimens for anatomical studies. Macedonian J Med Sci. 2012;5:5-9.

29. Langfield T, Colthorpe K, Ainscough L. Online instructional anatomy videos: student usage, self-efficacy, and performance in upper limb regional anatomy assessment. Anat Sci Educ. 2018;11:46170 .

30. Iwanaga J, Loukas M, Dumont AS, Tubbs RS. A review of anatomy education during and after the COVID-19 pandemic: revisiting traditional and modern methods to achieve future innovation. Clin Anat. 2021;34:108-14.

31. Rai R, Shereen R, Protas M, Greaney C, Brooks KN, Iwanaga J, et al. Social media and cadaveric dissection: a survey study. Clin Anat. 2019;32:1033-41.

32. Jaffar AA, Eladl MA. Engagement patterns of high and low academic performers on Facebook anatomy pages. J Med Educ Curric Dev. 2016;20:3.

33. Fasel JH, Aguiar D, Kiss-Bodolay D, Montet X, Kalangos A, Stimec BV, et al. Adapting anatomy teaching to surgical trends: a combination of classical dissection, medical imaging, and 3D-printing technologies. Surg Radiol Anat. 2016;38:361-7.

34. Peterson DC, Mlynarczyk GS. Analysis of traditional versus threedimensional augmented curriculum on anatomical learning outcome measures. Anat Sci Educ. 2016;9:529-36.

35. Chytas D, Johnson EO, Piagkou M, Mazarakis A, Babis GC, Chronopoulos E, et al. The role of augmented reality in anatomical education: an overview. Ann Anat. 2020;229:151463.

36. Birbara NS, Sammut C, Pather N. Virtual reality in anatomy: a pilot study evaluating different delivery modalities. Anat Sci Educ. 2020;13:445-57.

37. Stojanovska M, Tingle G, Tan L, Ulrey L, Simonson-Shick S, Mlakar J, et al. Mixed reality anatomy using Microsoft HoloLens and cadaveric dissection: a comparative effectiveness study. Med Sci Educ. 2020;30:173-8.

38. Biaggi P, Nijhof N, Corti R. Automated anatomical intelligence: next-generation fusion imaging during structural heart interventions. Eur Heart J. 2017;38:1412.

39. Choi-Lundberg DL, Cuellar WA, Williams AM. Online dissection audio-visual resources for human anatomy: undergraduate medical students' usage and learning outcomes. Anat Sci Educ. 2016;9(6): $545-54$.

40. Netter FH. Netter 3D Anatomy. Philadelphia: Elsevier; 2014. http:// netter3danatomy.com Accessed 20 Aug 2020)

41. Moszkowicz D, Duboc H, Dubertret C, Roux D, Bretagnol F. Daily medical education for confined students during coronavirus disease 2019 pandemic: a simple videoconference solution. Clin Anat. 2020;33:927-8.

42. Vodovar D, Ricard JD, Zafrani L, Weiss E, Desrentes E, Roux D. Évaluation d'un enseignement multimodal intégrant du e-learning dans l'apprentissage de la réanimation et de la médecine d'urgence au cours du second cycle des études médicales [Assessment of a newly-implemented blended teaching of intensive care and emergency medicine at Paris-Diderot University]. Rev Med Interne. 2020;41(6):368-74. 
43. Ross CF, Pescitelli MJ, Smith HF, Williams JM. Teaching anatomy with dissection in the time of COVID-19 is essential and possible. Clin Anat. 2020. Available at: https://doi.org/10.1002/ca.23640.

44. Mathiowetz V, Yu CH, Quake-Rapp C. Comparison of a gross anatomy laboratory to online anatomy software for teaching anatomy. Anat Sci Educ. 2016;9:52-9.

45. Evans DJR, Bay BH, Wilson TD, Smith CF, Lachman N, Pawlina W. Going virtual to support anatomy education: a STOPGAP in the midst of the Covid-19 pandemic. Anat Sci Educ. 2020;13(3):27983.

46. Gillett-Swan J. The challenges of online learning: supporting and engaging the isolated learner. J Learn Des. 2017;10:20-30.

47. Krähenbühl SM, Čvančara P, Stieglitz T, Bonvin R, Michetti M, Flahaut M, et al. Return of the cadaver. Key role of anatomic dissection for plastic surgery resident training. Medicine. 2017;96: e7528.

48. D Souza A, Kotian SR, Pandey AK, Rao P, Kalthur SG. Cadaver as a first teacher: A module to learn the ethics and values of cadaveric dissection. J Taibah Univ Med Sci. 2020;15:94-101.

49. Stephens GC, Rees CE, Lazarus MD. How does donor dissection influence medical students' perceptions of ethics? A cross-sectional and longitudinal qualitative study. Anat Sci Educ. 2019;12:332-48.

50. Drake RL, McBride JM, Pawlina W. An update on the status of anatomical sciences education in United States medical schools. Anat Sci Educ. 2014;7:321-5.

51. Whelan A, Leddy JJ, Ramnanan CJ. Benefits of extracurricular participation in dissection in a prosection-based medical anatomy program. Anat Sci Educ. 2018;11:294-302.

52. Smith CF, McManus B. The integrated anatomy practical paper: a robust assessment method for anatomy education today. Anat Sci Educ. 2015;8:63-73.

53. Brassett C, Cosker T, Davies DC, Dockery P, Gillingwater TH, Lee TC, et al. COVID-19 and anatomy: stimulus and initial response. J Anat. 2020;37:393-403.

54. The Alliance Review: Pandemic limits body donations for research. Available at: https://www.the-review.com/news/20200607/ pandemic-limits-body-donations-for-research (Accessed: 20 August 2020).

55. Pather N, Blyth P, Chapman JA, Dayal MR, Nams F, Fogg QA, et al. Forced disruption of anatomy education in Australia and New Zealand: An acute response to the Covid-19 pandemic. Anat Sci Educ. 2020;13:284-300.

56. Deccan Herald: COVID-19 Pandemic takes a toll on body donations in Bengal. Available at: https://www.deccanherald.com/ national/east-and-northeast/covid-19-pandemic-takes-a-toll-onbody-donations-in-bengal-871072.html (Accessed: 20 August 2020).

57. Livemint: 21 ESIC Hospitals converted into dedicated COVID-19 hospitals: 10 Points. Available at: https://www.livemint.com/ politics/policy/21-esic-hospitals-converted-into-dedicated-covid19-hospitals-10-points-11596959218970.html (Accessed: 20 August 2020).

58. The Hindu Business Line: 22 Private medical colleges converted into COVID-19 hospitals. Available at: https://www. thehindubusinessline.com/news/national/22-private-medicalcolleges-converted-into-covid-19-hospitals/article31292036.ece (Accessed: 20 August 2020).

59. Pacific Business News: University of Hawaii pauses willed body program due to COVID-19. Available at: https://www.bizjournals. com/pacific/news/2020/07/10/uh-pauses-willed-body-programdue-to-covid-19.html (Accessed: 20 August 2020).

60. UC San Diego school of medicine: Body Donation Program. Available at: https://medschool.ucsd.edu/educa) tion/bodydonation/Pages/default.aspx (Accessed: 20 August 2020).
61. Winichakoon P, Chaiwarith R, Liwsrisakun C, Salee P, Goonna A, Limsukon A, et al. Negative nasopharyngeal and oropharyngeal swabs do not rule out COVID-19. J Clin Microbiol. 2020;58: e00297-20.

62. AL-Tawfiq JA. Asymptomatic coronavirus infection: MERS-CoV and SARS-CoV-2 (COVID-19). Travel Med Infect Dis. 2020;35: 101608.

63. Mizumoto K, Kagaya K, Zarebski A, Chowell G. Estimating the asymptomatic proportion of coronavirus disease 2019 (COVID-19) cases on board the diamond princess cruise ship, Yokohama, Japan, 2020. Euro Surveill. 2020;25(10):2000180.

64. Liu Z, Chu R, Gong L, Su B, Wu J. The assessment of transmission efficiency and latent infection period in asymptomatic carriers of SARS-CoV-2 infection. Int J Infect Dis. 2020;99:325-7.

65. Kampf G, Todt D, Pfaender S, Steinmann E. Persistence of coronaviruses on inanimate surfaces and their inactivation with biocidal agents. J Hosp Infect. 2020;104:246-51.

66. Xiao F, Sun J, Xu Y, Li F, Huang X, Li H. Infectious SARS-CoV-2 in feces of patient with severe COVID-19. Emerg Infect Dis. 2020;26:1920-2.

67. Davidson SS, Benjamin WH. Risk of infection and tracking of work-related infectious diseases in the funeral industry. Am J Infect Control. 2006;34:655-60.

68. van Overmeire R, Bilsen J. COVID-19: the risks for funeral directors. J Public Health (Oxf). 2020;42:655.

69. Aljerian K, Bahammam AS. COVID-19: lessons in laboratory medicine, pathology, and autopsy. Ann Thorac Med. 2020;15: $138-45$.

70. Sriwijitalai W, Wiwanitkit V. COVID-19 in forensic medicine unit personnel: observation from Thailand. J Forensic Legal Med. 2020;72:101964.

71. Yaacoub S, Schünemann HJ, Khabsa J, El-Harakeh A, Am K, Chamseddine F, et al. COVID-19 Systematic Urgent Reviews Group Effort (SURGE) Group. Safe management of bodies of deceased persons with suspected or confirmed COVID-19: A rapid systematic review. BMJ Glob Health. 2020;5:e02650.

72. Patel M, Khatri S, Shree JR, As P, Agrawal P, Sinha A. Conceptual design of a body bag for preventing infections and safe disposal of deceased from COVID-19 Virus. Trans Indian Natl Acad Eng. 2020;5:429-35.

73. Jiang W, Schwendeman SP. Formaldehyde-mediated aggregation of protein antigens: comparison of untreated and formalinized model antigens. Biotechnol Bioeng. 2020;70:507-17.

74. Balta JY, Cronin M, Cryan JF, O'mahony SM. Human preservation techniques in anatomy: a 21st century medical education perspective. Clin Anat. 2015;28:725-34.

75. Crubézy E, Telmon N. Pandemic-related excess mortality (COVID19), public health measures and funerary rituals. EClinicalMedicine. 2020;22:100358.

76. Tian Y, Rong L, Nian W, He Y. Review article: gastrointestinal features in COVID-19 and the possibility of faecal transmission. Aliment Pharmacol Ther. 2020;51:843-51.

77. Centers For Disease Control and Prevention (CDC). Coronavirus Disease 2019 (COVID-19): Interim guidelines for collecting, handling, and testing clinical specimens for COVID-19. 2020. Available at: https://www.cdc.gov/coronavirus/2019-ncov/lab/ guidelines-clinical-specimens.html (Accessed 20 August 2020).

Publisher's Note Springer Nature remains neutral with regard to jurisdictional claims in published maps and institutional affiliations. 